\title{
Mother nature's fury: Antagonist metaphors for natural disasters increase forecasts of their severity and encourage evacuation
}

\author{
David J. Hauser ${ }^{\mathrm{a}}$ \& Megan E. Fleming ${ }^{\mathrm{b}}$ \\ ${ }^{a}$ Queen's University, Department of Psychology, Craine 320, 62 Arch St, Kingston, Ontario, \\ K7L3N6, Canada, email: david.hauser@queensu.ca, Twitter: @ davidjhauser, \\ CORRESPONDING AUTHOR \\ ${ }^{\mathrm{b}}$ Queen's University, School of Kinesiology and Health Studies, Room 301T, 28 Division St, \\ Kingston, Ontario, K7L3N6, email: megan.fleming@queensu.ca
}

In press at Science Communication

Word count: 9300 words

\section{Acknowledgements and funding details}

We wish to thank Milong Wang, Andrew Hall, and the members of Queen's MaSC Lab for conversations about the research and Elze Orr, Ninya Stein, Maddy Prosserman, and Kyla Shaw for assistance with the research. The authors declare no financial conflicts of interest. This work was supported by the Social Sciences and Humanities Research Council of the Government of Canada (grant number 430-2019-00009).

Please address all correspondence to David J. Hauser, Queen's University, Department of Psychology, Craine 320, 56 Arch St, Kingston, ON K7L 3L3, Canada; david.hauser@queensu.ca 


\begin{abstract}
Natural disasters are often described as having antagonistic qualities (e.g., wildfires ravage). The information deficit model presumes that when people assess the risk of weather hazards, they ignore irrelevant metaphoric descriptors. However, metaphoric frames impact reasoning. The current research assessed whether antagonist metaphors for natural disasters impact perceptions of the risk they pose. Three studies $(\mathrm{N}=1,936)$ demonstrated that participants forecasted an antagonist-framed natural hazard as being more severe, and intended to evacuate more often, than a literal-framed natural hazard. Thus, the metaphorical language used to discuss natural disasters deserves consideration in the development of effective risk communication.

Keywords: conceptual metaphor, risk communication, natural disasters, risk perception $<99 / 100$ words $>$
\end{abstract}




\section{Mother nature's fury: Antagonist metaphors for natural disasters increase forecasts of their severity and encourage evacuation}

Public responses to natural disasters are often contingent upon how the risks of such events are communicated (Glik, 2007). Public health agencies often employ an information deficit model of risk communication (Eisenman et al., 2007). According to this model, agencies merely need to provide the public with the necessary information about risk and danger in order for people to make rational decisions (Owens, 2000).

However, this model often fails because of flaws in human decision-making. Humans are poor statistical reasoners, often neglecting or failing to understand diagnostic information (Kahneman \& Tversky, 1973). Such processes have endangered lives in the past. As an example, many residents of New Orleans risked remaining during Hurricane Katrina despite public announcements of severe danger and orders of mandatory evacuation. In post-event interviews, those who remained mentioned that they "didn't take the messages seriously" and that there was more danger in facing the evacuation-caused traffic than in remaining (Eisenman et al., 2007, p. S111). An estimated 1,500 people died in Louisiana alone (CNN, 2019). Quite simply, people often fail to understand risk and severity when it is communicated to them.

How, then, can communicators convey risk of natural disasters? The current studies investigate the potential of antagonist metaphor frames.

Natural disasters are often framed with antagonist metaphors (Matlock et al., 2017). Wildfires ravage forests. Hurricanes pummel shorelines. Floods creep through cities. These metaphors are unlikely to be mere linguistic flourishes. This is because, according to conceptual metaphor theory, representation for abstract, difficult-to-grasp concepts is scaffolded upon easier-to-understand source domains (for overviews, see Lakoff \& Johnson, 1980; Gentner, 
1983; Gibbs, 1994; Landau et al., 2010). Such relations are evident in the language commonly used to discuss these domains. For instance, phrases like "wash away the past" demonstrates an abstract representation of REMOVAL as WASHING (Lee \& Schwarz, 2011), and phrases like "spend some time together" demonstrates an abstract representation of TIME as MONEY (Lakoff \& Johnson, 1980).

Importantly, conceptual metaphor theory also suggests that metaphoric framing guides reasoning (for reviews, see Thibodeau et al., 2017; Holyoak \& Stamenković, 2018; Thibodeau et al., 2019). When one comprehends an abstract concept that is metaphorically framed, a conceptual metaphor is activated. The mapping of source concept to target domain highlights attributes (i.e., entailments) of the framed concept that align with the source. These highlighted attributes are brought to front-of-mind, providing an easy-to-understand schematic framework for evaluating, reasoning, and making inferences related to the target concept (Landau, Meier, \& Keefer, 2010). For instance, framing crime as a beast (vs virus) highlights punitive solutions to a crime wave (Thibodeau \& Boroditsky, 2011), framing love as a journey (vs oneness) makes romantic disputes seem more temporary (Lee \& Schwarz, 2014), and framing stocks as agents (vs literally) makes them seem like they will continue their course of action (Morris et al., 2007). Seemingly innocuous metaphoric language affects the perceived danger of aversive entities in many domains (climate change - Flusberg, et al., 2017; ultraviolet radiation - Landau et al., 2018; cancer - Hauser \& Schwarz, 2015; influenza - Scherer, et al., 2015; and wildfires - Matlock et al., 2017). Quite simply, metaphoric descriptors guide the inferences people draw about abstract concepts, be it through structure mapping or affective processes (Thibodeau et al., 2019).

People often fail to comprehend risk when it is communicated to them (Eisenman et al., 2007). Thus, the information deficit model cannot fully account for decision-making in response 
to risk communication for natural disasters. The mere communication of risk often falls short in effectively conveying danger because people have mental models of risks that may not resonate with communications. Mental models are lay beliefs, associations, or conceptual metaphors for how difficult-to-understand things work (Johnson-Laird, 1983; Morgan et al., 2002). People use mental models to reason in many domains, and the descriptors that people and media use to describe risks provide clues as to the common mental models that a population holds (Morgan et al., 2002). Similar to metaphor matching effects (Hauser \& Schwarz, 2015; Thibodeau \& Durgin, 2011), information about risks that fits or complements those mental models is more likely to be accepted and heeded than information that contradicts them (Morgan et al., 2002). Thus, using prevalent metaphorical descriptors of natural disasters in risk communications may resonate with a common mental model, thereby impacting risk perception.

Even though antagonist metaphors are prevalent frames for communicating natural disasters (Matlock et al., 2017), these metaphors have been documented to have a wide array of effects on risk perception (for a review, see Flusberg et al., 2018). They motivate risk-reducing behaviours in some domains (Flusberg et al., 2017; Landau et al., 2018; Matlock et al., 2017, Scherer, et al, 2015), while they demotivate risk-reducing behaviours in others (Hauser \& Schwarz, 2015; 2020). War metaphors are particularly influential because wars are easily understood concepts with well-defined attributes. Wars resemble many other concepts, and war metaphors are conventional communicative tools. They tend to evoke emotions of fear and conceptually emphasize conflict and victory/defeat (Flusberg et al., 2018). However, the effect of any metaphoric frame is often dependent upon the particular lexicalized metaphors used, the manner in which they are used, and the particular concept that is framed. Thus, it is hard to know which particular inferences a metaphor will promote for a given domain, or even if it will have 
an effect at all without empirical studies (Flusberg et al., 2018; Hauser et al., 2017; Hauser \& Schwarz, 2016).

Additionally, one potential boundary condition is of particular importance for natural disaster risk communication. Many posit that metaphoric framing only impacts reasoning about ambiguous concepts (Hauser \& Schwarz, 2015; Keefer et al., 2011; Landau et al., 2014). Metaphoric frames guide reasoning for ambiguous judgments but have little impact on unambiguous judgments (Robins \& Mayer, 2000). This suggests that metaphoric entailments serve as stand-in knowledge when people lack the necessary information, but when more diagnostic information is available, metaphoric framing has little to no effect. An analogue is found in set size principles in conceptual accessibility effects (Anderson, 1971; Higgins, 1996). Just like accessible concepts, metaphoric entailments are merely one piece of information, the impact of which should be significantly diluted when other diagnostic information is available or when judgements are unambiguous.

On the other hand, metaphoric framing effects may not be bounded to merely ambiguous judgments. Metaphoric framing effects have been observed even when metaphoric information is presented in tandem with other substantive information (Hauser \& Schwarz, 2015; Scherer et al., 2015; Flusberg et al., 2017). Similar to the primacy effect in person impression (Asch, 1946), metaphoric frames may colour the way that even unambiguous information is processed, guiding inferences in line with metaphoric entailments (Thibodeau \& Boroditsky, 2011).

If metaphoric framing only affects reasoning about ambiguous concepts, then metaphors for natural disasters would only impact risk perception when relatively little diagnostic information is available (i.e., in limited circumstances). However, if metaphoric framing is not bounded to ambiguous judgments, then metaphors for natural disasters may impact risk 
perception even when ample diagnostic information is available (i.e., in most circumstances). We assess these possibilities in the last study.

A pilot, three studies, and a meta-analysis shed light on whether antagonist metaphors affect risk perception of natural disasters. We hypothesized that antagonist metaphors would individually and directly affect three distinct outcomes. Because antagonists are dangerous, antagonist-framed natural disasters should be perceived as more severe. Because people avoid others who seem to intend harm (Cuddy et al., 2008), antagonist-framed natural disasters should prompt more participants to express a willingness to evacuate. Finally, because antagonists provoke disaster-related stressors (e.g., threats to personal safety, difficulty finding food, etc) in popular narratives such as superhero movies, antagonist-framed natural disasters should increase predictions of encountering disaster-related stressors.

A pilot study first assesses whether antagonistic concepts are more associated with danger than other concepts. Studies 1 and 2 then assess whether seemingly innocuous metaphors relating hurricanes and floods to antagonists increase their perceived severity and increase evacuation intentions. Finally, Study 3 assesses boundary conditions of the effect, examining whether the antagonist metaphor only affects risk perception when little other diagnostic information about severity is provided or if it affects risk perception even in the presence of other diagnostic information.

We report all studies, manipulations, measures, and exclusions. The methods, predictions, and analyses for all studies were described a priori in detail in a grant application. The raw data, materials, and analysis code are openly available at https://osf.io/sgwe4/. Sample sizes, hypotheses, and analyses were determined a priori. All studies were approved by the author's 
research ethics board and were carried out in accordance with the Declaration of Helsinki for experiments involving humans. Informed consent was obtained for all experiments.

\section{Pilot study - Are antagonistic agents associated with danger?}

Conceptual metaphor studies often demonstrate how metaphorically framing a target concept as a source domain promotes inferences about the target that align with attributes of the source. However, many fail to empirically establish the emblematic attributes of source domains that differ between comparable metaphoric and literal frames. Without this pilot testing, there is little empirical basis for hypothesized effects of metaphoric framing. In this section, we aim to provide empirical grounds for the hypotheses in the forthcoming studies by leveraging semantic word embedding models.

Grounding predictions about metaphors via intuitions alone is problematic as the meaning of metaphors and idioms is not inherently transparent (Keysar \& Bly, 1995). However, semantic embedding models apply machine learning algorithms to text corpora to derive metrics of relatedness between concepts. Associations are determined by the distributive properties of words in natural language. The resulting outputs can be used to model human decision-making with a high degree of accuracy (Bhatia, 2017), supply an ecologically valid index of conceptual associations (Mikolov et al., 2013), and can even capture implicit biases (Caliskan et al., 2017).

Conceptual metaphor theory (Lakoff \& Johnson, 1980) posits that metaphorically framing a target domain (such as a natural disaster) in terms of a source domain (such as an antagonist) confers emblematic attributes of the source domain (such as the dangerousness of antagonists) to the target domain. We used semantic embedding models to lend empirical data for whether the source domain of antagonists has the emblematic attributes that we intuit it has. That is, we investigate whether the concept of antagonists is strongly associated with danger, 
even moreso than the concept of vehicles, which serves as a control metaphoric framing in future studies. If so, this would provide empirical justification for the research question explored in the forthcoming studies.

\section{Method}

To assess semantic embeddings, we utilized an abbreviated version of a pre-trained word embedding dataset of word2 $\mathrm{vec}$ on the Google News corpus. The original dataset contains 3 million word vectors (Mikolov et al., 2013) and has been validated in prior research (Caliskan et al., 2017); we utilized an abbreviated version that contained the most frequent 100,000 words in the corpus because the words we investigated were among these most frequent words.

We first compiled groups of words to test: antagonist words (e.g., enemy, monster, beast); vehicle words (e.g., vehicle, car, automobile); and a random selection of 1000 words. These words were selected on the basis of their high association with the superordinate concepts of antagonists and vehicles and to what extent previous research has identified these words as common metaphoric frames for weather events (Matlock et al., 2017; Kilpijärvi, 2014; Landau et al., 2018). For instance, antagonist and vehicle items were words and synonyms that are commonly used to describe weather events as well as their behaviour (e.g., "striking" and "veering"). Vehicle words served as a control group, foreshadowing the forthcoming studies, while the random selection of 1000 words served as a second control group.

To what extent are antagonist words, vehicle words, and random words associated with danger? To assess this, we calculated the each group's average association with danger vs safety. We compute the average similarity score (i.e., cosine distance) of each word in each group to a set of danger attribute words (e.g., powerful, dangerous, deadly) and a set of safety attribute words (e.g., weak, safe, beneficial). Danger (safe) attribute words were words and synonyms that 
are frequently used to describe hazardous (nonhazardous) entities (Davies, 2016). For each group of test words, we calculated the effect size $(g)$ and $95 \%$ confidence interval for the difference of similarity to dangerous vs safe words, such that positive (negative) numbers represent association with danger (safe) words and zero represents no association. For the words and code, see https://osf.io/sgwe4/.

As shown in Figure 1, results confirmed predictions. Semantic embeddings identified our antagonist agent concepts as being significantly associated with danger (relative to safety), $g=$ $1.35,95 \%$ CI $[1.02,1.69]$. Additionally, vehicle concepts were also significantly associated with danger (relative to safety), $g=0.65,95 \%$ CI $[0.34,0.96]$. However, as evidenced by the nonoverlapping confidence intervals, antagonist concepts were significantly more associated with danger than vehicle concepts. Finally, a random selection of 1000 test words showed a small but significant association with danger (relative to safety), $g=0.12,95 \% \mathrm{CI}[0.08,0.15]$. However, this is perhaps not surprising since the semantic embeddings are derived from a corpus of news articles, which tend to focus on danger and risk. Therefore, we conclude that antagonist-related concepts emphasize danger more so than vehicle-related concepts, suggesting that antagonist metaphor frames should be more associated with danger than vehicle metaphor frames. We note that while vehicle concepts were more associated with danger than the random selection of words, we hesitate to ground predictions for comparing vehicle frames to literal frames. This is because a random selection of 1000 words is not a suitable analogue for a literal message discussing an incoming severe weather event. 


\section{Figure 1}

Semantic embeddings of antagonist words, vehicle words, and a random selection of 1000 words with danger attribute words (positive) vs safe attribute words (negative).

\section{Concept}

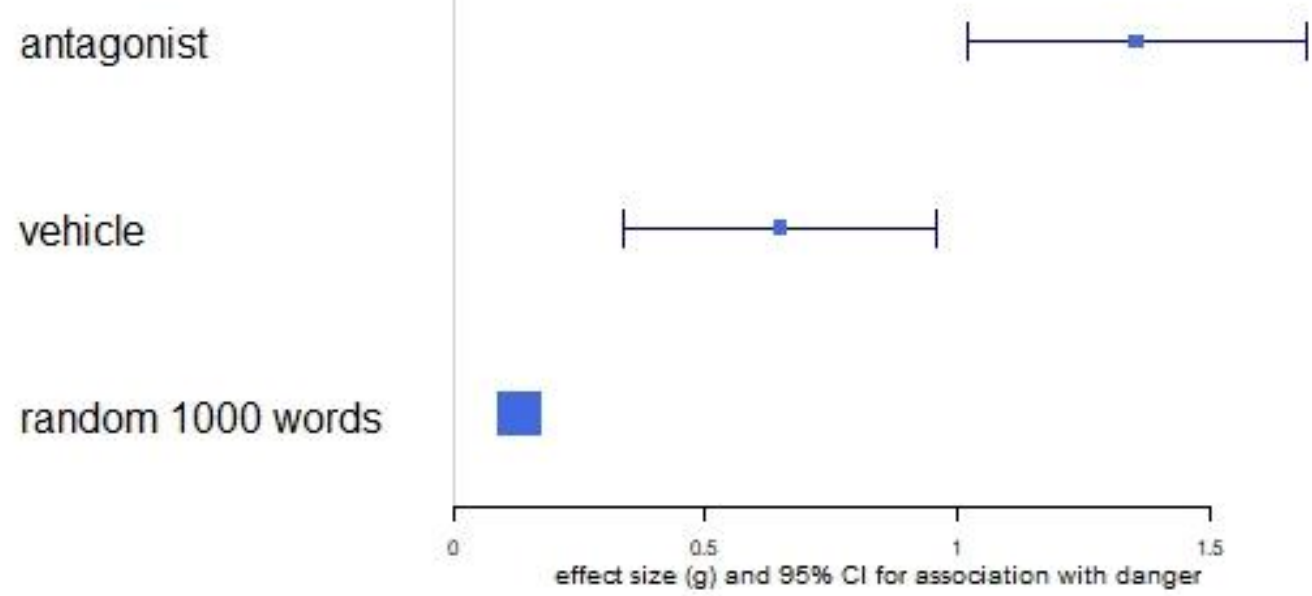

Note. Antagonist words are significantly more associated with danger than are vehicle words and 1000 randomly selected words.

\section{Study 1 - Does antagonist framing increase the perceived danger of a hurricane?}

Because antagonists are dangerous, metaphorically framing a hurricane as an antagonist should confer such qualities to the hurricane, increasing forecasts of its severity, encouraging intentions to evacuate, and increasing forecasts of disaster-related stressors following the hurricane. Study 1 explores these hypotheses.

Participants imagined they faced an incoming hurricane that varied in framing (literal, vehicle metaphor, antagonist metaphor). Literal and vehicle metaphor framing conditions served as two control conditions against which to compare the effect of antagonist metaphor framing. Participants then forecasted the extent of the damage, indicated whether they would evacuate, and forecasted the likelihood of disaster-related stressors. 


\section{Method}

\section{Participants}

Based on prior research (Matlock et al., 2017), we sought an $N=390$ to achieve $80 \%$ power for detecting an effect size between independent groups of $d=.35$ (Faul et al., 2009). Four hundred and twenty-five American workers from Amazon Mechanical Turk (MTurk) initiated the study in exchange for 52 cents. Following best-practice recommendations, workers were required to have 100 prior accepted HITs (Human Intelligence Tasks, i.e., surveys on the platform) and a HIT acceptance ratio of $95 \%$ or higher (Hauser \& Schwarz, 2016; Hauser et al., 2019). The median time to complete the survey was 3 minutes. Thirty-three participants did not complete the survey, and an additional 29 participants did not pass the comprehension check questions that appeared at the end of the survey. Dropouts and comprehension check failure did not differ by metaphor manipulation. This left us with a final sample of 363 participants (182 males; age range $20-78$ ).

\section{Materials and Procedure}

Participants were directed to an English-language online survey on reasoning about hurricanes, where they imagined themselves facing an incoming hurricane that was framed in one of three ways (literal, vehicle metaphors, antagonist metaphors; randomly assigned). The hurricane scenario follows with manipulations shown in parentheses and conditions displayed in the aforementioned order:

You live in Nags Head, North Carolina, a beach town on the Atlantic coast. The local news reports that a storm, Hurricane Lee, has formed in the Atlantic Ocean. The reporter states "Hurricane Lee has already (swept through / rumbled over / battered) the Virgin Islands. Now it is (gaining energy / refueling / gaining strength) in the 
Atlantic and is (predicted to make landfall at / veering towards / poised to strike)

Nags Head. The National Guard has been called in (to help / to help / as reinforcements), but it appears as if Nags Head will soon (feel Hurricane Lee's arrival / be Hurricane Lee's next stop / feel Hurricane Lee’s fury)."

Participants then forecasted the severity of the storm. In text entry boxes, they estimated how many homes would be destroyed, how many lives would be lost, and how many days the city would be without power. They also indicated whether they would intend to evacuate if they were in this situation (yes/no), and how much damage they thought would result from the hurricane on a 5-point scale $(1=$ no damage, constructions are mostly unaffected; $5=$ considerable damage, most constructions will be destroyed). Question order was randomized.

On a separate survey page, participants rated how worried, fearful, and anxious they would be about the hurricane on 7 -point scales $(1=$ not at all, $7=$ very much). Item order was randomized. Hurricane framing did not affect responses to these questions as most responses were at the top of the scale (the median response to each was 6), so these questions will not be discussed further.

On another survey page, participants estimated the likelihood of encountering hurricanerelated stressors - robbery, difficulty finding food, difficulty finding warmth, difficulty finding gasoline, threats to personal safety - in the aftermath of the storm on a 7-point scale $(1=$ not at all likely, 7 = extremely likely; adapted from Kujawa et al., 2015). Item order was randomized.

On the next survey page, participants imagined that their home was destroyed in the hurricane and rated their emotional response and who was to blame. Hurricane framing had no impact on these measures either, so they will not be discussed further. 
Finally, participants described what the opening scenario was about (text entry box) and described the content of a picture of potatoes (text entry box) as indices of attention (Litman \& Robinson, 2020). A research assistant (and now co-author), blind to condition, coded responses for accuracy. Participants also provided demographic information (gender, age, occupation, household income, education, political orientation, and state of residence) before being debriefed and compensated.

\section{Results and Discussion}

Because antagonists are dangerous, metaphorically framing a hurricane as an antagonist should confer such qualities to the hurricane, increasing forecasts of its severity. As shown in Table 1, this hypothesis was supported for open-ended forecasts of severity across all items ${ }^{1}$. Antagonist framing of the hurricane consistently increased participants' forecasts of the number of homes destroyed, lives lost, and days without power caused by the hurricane.

\section{Table 1.}

Responses to open-ended forecasts of severity [5\% trimmed mean \& median (SD)] by metaphor in Study 1

\begin{tabular}{lrrr}
\hline Framing & $\begin{array}{r}\text { How many homes } \\
\text { destroyed? }\end{array}$ & $\begin{array}{r}\text { How many lives } \\
\text { lost? }\end{array}$ & $\begin{array}{r}\text { How many days } \\
\text { without power? }\end{array}$ \\
\hline Literal & $572,100(3452)$ & $25,10(937)$ & $8,7(31)$ \\
Vehicle & $508,150(15411)$ & $20,10(77)$ & $8,6(14)$ \\
Antagonist & $654,200(5147)$ & $49,21(411)$ & $10,8(9)$ \\
\hline Omnibus test & $H(2)=9.90, p=.007$ & $H(2)=19.55, p<.001$ & $H(2)=9.47, p=.009$ \\
\hline Planned contrasts & & & \\
Literal v antagonist & $U=6381, z=3.06, p$ & $U=6034, z=3.65, p$ & $U=6972, z=2.07, p$ \\
& $=.002, d=.39$ & $<.001, d=.47$ & $=.039, d=.26$ \\
Vehicle v antagonist & $U=5911, z=2.08, p$ & $U=4945, z=3.92, p$ & $U=5455, z=2.96, p$ \\
& $=.037, d=.27$ & $<.001, d=.52$ & $=.003, d=.39$ \\
\hline
\end{tabular}

\footnotetext{
${ }^{1}$ Levene's test indicated that there were violations of the heterogeneous variances assumption for all but one of the severity items (homes destroyed $p=.008$; lives lost $p=.032$; days without power $p=.280$; and damage $p=.001$ ), so we used nonparametric tests - Kruskal-Wallis tests for omnibus tests and Mann-Whitney U tests for planned contrasts.
} 
As shown in Table 2 (first column), the same was true for close-ended forecasts of hurricane damage. Antagonist framing increased participants' forecasts of hurricane damage relative to literal framing and to vehicle framing. Over several measures of severity, hurricanes that are "poised to strike" are forecasted as being more severe than those that "veer" or those that "make landfall".

Table 2.

Average responses to close-ended dependent measures by metaphor in Study 1

\begin{tabular}{|c|c|c|c|}
\hline Framing & $\begin{array}{r}\text { How much damage? } \\
(1=\text { none, } \\
5=\text { considerable }\end{array}$ & $\begin{array}{r}\text { Would you evacuate? } \\
\text { (yes vs no) }\end{array}$ & $\begin{array}{r}\text { How likely are stressors? } \\
(1=\text { not at all, } \\
7=\text { extremely })\end{array}$ \\
\hline Literal & $3.83(0.70)$ & $90 \%$ yes & $5.2(1.31)$ \\
\hline Vehicle & $3.64(0.66)$ & $88 \%$ yes & $4.8(1.32)$ \\
\hline Antagonist & $4.01(0.61)$ & $96 \%$ yes & $5.4(1.14)$ \\
\hline Omnibus test & $H(2)=16.91, p<.001$ & $\begin{array}{r}\chi^{2}(2, N=363)=6.08, p \\
=.048\end{array}$ & $H(2)=5.48, p=.065$ \\
\hline \multicolumn{4}{|c|}{ Planned contrasts } \\
\hline $\begin{array}{l}\text { Literal v } \\
\text { antagonist }\end{array}$ & $\begin{array}{r}U=7066, z=2.17, p \\
=.030, d=.24\end{array}$ & $\begin{array}{r}\chi^{2}(1, N=256)=4.24, p \\
=.039, \varphi=.13\end{array}$ & $\begin{array}{r}U=7766, z=0.71, p= \\
.476, d=.09\end{array}$ \\
\hline $\begin{array}{l}\text { Vehicle } \mathrm{v} \\
\text { antagonist }\end{array}$ & $\begin{array}{r}U=5080, z=4.11, p \\
<.001, d=.49\end{array}$ & $\begin{array}{r}\chi^{2}(1, N=238)=5.85, p \\
=.016, \varphi=.16\end{array}$ & $\begin{array}{r}U=5695, z=2.38, p= \\
.017, d=.31\end{array}$ \\
\hline
\end{tabular}

Note. Average responses per metaphor framing condition for "how much damage" are 5\% trimmed means (SD), for "would you evacuate" are the proportion saying yes, and for "how likely are stressors" are medians (SD).

Because antagonists are best avoided, we also hypothesized that this framing would increase intentions to evacuate. As shown in Table 2 (second column), that hypothesis was also supported. Significantly more participants intended to evacuate an antagonist-framed hurricane than a literal-framed hurricane and a vehicle-framed hurricane. Thus, more people intend to evacuate a "furious" hurricane more than one that makes "stops" or that "arrives". 
Because antagonists provoke disaster-related stressors, we hypothesized that antagonistframed hurricanes would be more associated with expectations of encountering them ${ }^{2}$. As shown in Table 3 (third column), this hypothesis was partially supported. Antagonist framing increased forecasts of disaster-related stressors compared to vehicle framing but had no effect on forecasts of disaster-related stressors compared to literal framing. Thus, antagonist framing partially increases forecasts of disaster-related stressors in the aftermath of a hurricane. However, effects were marginal and did not fulfil the hypothesized pattern's entirety, so we first sought to replicate this effect in another study before interpreting it.

\section{Study 2 - Does antagonist framing increase the perceived danger of a flood?}

Flooding is the costliest natural disaster in Canada in terms of property damage and floods attract significant media attention (Public Safety Canada, 2018). Thus, Study 2 was assessed generalizability of antagonist metaphors by conceptually replicating their effects on perceptions of flood severity. Participants imagined they faced a flash flood warning that varied in metaphoric framing (vehicle vs antagonist). Pretesting indicated that participants found the literal flood message to be less vivid than the metaphorically framed flood messages. In metaphor research, literal frames are seldom true "neutral" frames because they often differ from metaphorical frames in several dimensions such as valence, vividness, conventionality, and arousal (Thibodeau \& Boroditsky, 2015). Thus, Study 2 utilized no literal framing condition.

Because antagonists are dangerous, metaphorically framing a flood as an antagonist should confer such qualities to the event, increasing forecasts of its severity. Additionally,

\footnotetext{
${ }^{2}$ A principal components analysis indicated that forecasts of encountering disaster-related stressors in the aftermath of the hurricane (robbery, difficulty finding food, difficulty finding warmth, difficulty finding gasoline, threats to personal safety) all loaded positively, with all loadings over .71, onto a single factor solution that explained $60 \%$ of the variance. Thus, items were averaged to create an index of forecasts of disaster-related stressors $(\alpha=.83)$. Once again, Levene's test indicated the heterogeneous variances assumption was violated $(p=.046)$. Thus, we turned to nonparametric tests: Kruskal-Wallis tests for omnibus tests and Mann-Whitney U tests for planned contrasts.
} 
because antagonists are best avoided, such metaphors should encourage intentions to evacuate. Finally, because antagonists provoke disaster-related stressors, metaphorically framing a flood as one should increase expectations of encountering them following the event. Study 2 explores these hypotheses.

\section{Method}

\section{Participants}

Based on Study 1's average effect size $(d=.30)$, we sought an $n=300$ per group to achieve $95 \%$ power for detecting an effect of that size between independent groups (Faul et al., 2009). Six hundred and fifty-five American and Canadian workers from MTurk initiated the survey in exchange for 45 cents. Following best-practice recommendations, workers were required to have not participated in Study 1, have 100 prior accepted HITs, and a HIT acceptance ratio of $95 \%$ or higher (Hauser et al., 2019). The median time to complete the survey was 2 minutes. Nineteen participants did not complete the measures, but attrition did not differ by metaphor manipulation. This left us with a final sample of 636 participants (320 men; 301 women; 4 non-binary; 11 preferred not to answer; age range: 18 -99).

\section{Materials and Procedure}

Participants were directed to an English-language online survey about reasoning about natural disasters, where they imagined themselves caught in a flash flood warning that was metaphorically framed as a vehicle or an antagonist (randomly assigned). The scenario follows with manipulations shown in parentheses in the aforementioned order:

You live in downtown Kingston, Ontario, a moderately-sized town on the banks of Lake Ontario. The local news reports that, as a result of heavy rainfall in the area, your town is under a flash flood warning. The reporter states, "The (flood / monster 
flood) has already (reached / struck) neighbourhoods on the outskirts of town.

Unfortunately, there is no way to (stop / contain) it. There is concern that it will (veer / creep) into downtown overnight and (affect / threaten) the area. Canadian Armed

Forces have been called in (to help / to tame it)."

Participants then forecasted the severity of the flood by estimating how much damage they thought would result from the flood on a 5 -point scale $(1=$ no damage; $5=$ considerable damage). They also indicated whether they would intend to pack an evacuation bag and emergency kit if they were in this situation (no/yes). Question order was randomized.

On another survey page, participants estimated the likelihood of encountering disasterrelated stressors - robbery, difficulty finding food, difficulty finding warmth, difficulty finding gasoline, threats to personal safety - in the aftermath of the flood on a 7-point scale $(1=$ not at all likely, 7 = extremely likely; adapted from Kujawa et al., 2015). Item order was randomized.

Finally, participants also provided demographic information (gender, age, occupation, etc.) before being debriefed and compensated.

\section{Results and Discussion}

Because antagonists are dangerous, metaphorically framing a flood as an antagonist should confer such qualities to the event, increasing perceptions of its severity. As shown in Table 3 (first column), this was indeed the case ${ }^{3}$. A flood framed as an antagonist was forecasted as causing more damage than a flood framed as a vehicle. Similarly, because one avoids antagonists, we also hypothesized that this framing would increase intentions to evacuate. As shown in Table 3 (second column), it did. Antagonist framing also increased intentions to

\footnotetext{
${ }^{3}$ Levene's test for violations of the heterogeneous variance assumption approached significance for our severity measure $(p=.09)$. Because that same measure showed a similar violation in Study 1, we conducted a non-parametric test (Mann-Whitney U) for that item,
} 
evacuate. Thus, similar to an antagonist-framed hurricane, an antagonist-framed flood was

expected to be more severe and encouraged more people to evacuate than a vehicle-framed

flood.

Table 3.

Average responses to dependent measures by metaphor in Study 2

\begin{tabular}{|c|c|c|c|}
\hline Framing & $\begin{array}{r}\text { How much damage? } \\
(1=\text { none, } \\
5=\text { considerable }\end{array}$ & $\begin{array}{l}\text { Would you prepare to } \\
\text { evacuate? (yes vs no) }\end{array}$ & $\begin{array}{r}\text { How likely are } \\
\text { stressors? (1=not at all, } \\
7=\text { extremely) }\end{array}$ \\
\hline Vehicle & $3.88(0.81)$ & $86 \%$ yes & $4.87(1.28)$ \\
\hline Antagonist & $4.01(0.79)$ & $91 \%$ yes & $4.90(1.34)$ \\
\hline Statistical test & $\begin{array}{r}U=46115, z=2.05, p \\
=.041, d=.15\end{array}$ & $\begin{array}{r}\chi^{2}(1, N=636)=4.31 \\
p=.038, \varphi=.08\end{array}$ & $F<1$ \\
\hline
\end{tabular}

Note. Average responses per metaphor framing condition for "how much damage" are means (SD), for "would you evacuate" are the proportion saying yes, and for "how likely are stressors" are means $(\mathrm{SD})$.

Because antagonists provoke disaster-related stressors, we hypothesized that antagonist framing would promote forecasts of similar events following the flood ${ }^{4}$. However, in contrast to Study 1 , this hypothesis was not supported, $F<1$ for the effect of metaphor. Thus, antagonist framing may not impact forecasts of disaster-related stressors in the aftermath of natural disasters. Because this effect was not fully consistent with expectations in Study 1 and failed to generalize to floods in Study 2, we chose not to pursue it further in the last study.

\section{Study 3 - Does antagonist framing still portray danger when other information is} available?

\footnotetext{
${ }^{4}$ As in Study 1, forecasts of encountering disaster-related stressors in the aftermath of the flood (robbery, difficulty finding food, difficulty finding warmth, difficulty finding gasoline, threats to personal safety) were averaged to create an index of forecasts of disaster-related stressors $(\alpha=.87)$.
} 
The goal of Study 3 was to conceptually replicate the results of Study 2 while also investigating whether the effect generalizes to situations where additional risk information is provided.

Many posit that metaphoric framing only impacts reasoning about ambiguous concepts for which people have little information to draw upon (Hauser \& Schwarz, 2015; Keefer et al., 2011; Landau et al., 2014). Metaphoric frames guide reasoning for ambiguous judgments but have little impact on unambiguous judgments (Robins \& Mayer, 2000). Essentially, metaphoric entailments serve as stand-in knowledge when people lack the necessary information to make a decision. With more diagnostic information, metaphoric framing should have little to no effect. This suggests that an antagonist metaphor would only increase perceptions of severity when the severity of the event is ambiguous.

On the other hand, metaphoric framing guides the interpretation of available information in line with metaphoric entailments (Thibodeau \& Boroditsky, 2011). Essentially, metaphoric frames colour the way that diagnostic information is processed. This suggests that antagonist metaphors could encourage evacuation intentions even when severity information is provided. Thus, metaphor may function as diagnostic information for severity even when other suitable information is available.

This potential ambiguity boundary condition is of particular importance for natural disaster risk communication. Most warnings regarding weather hazards are accompanied by ample diagnostic information. If metaphoric framing only affects reasoning about ambiguous weather events, then their effects on risk perception may be limited. However, if metaphoric framing is not bounded to ambiguous judgments, then their effects may be more applicable to more ecologically valid circumstances. Study 3 addresses these possibilities. 


\section{Method}

\section{Participants}

Given the prior observed effect sizes for metaphor effects (Study $1 d=.3$; Study $2 d=$ .15 ), we sought a minimum $n=400$ per metaphor group (after exclusions) to achieve $80 \%$ power for detecting an effect size $d=.20$ between independent groups (Faul et al., 2009). One thousand four hundred and eight American and Canadian workers from MTurk initiated the survey in exchange for 30 cents. Following best-practice recommendations, workers were required to have not participated in Study 1 or Study 2, have 100 prior accepted HITs and a HIT acceptance ratio of $95 \%$ or higher (Hauser et al., 2019). The median time to complete the survey was 1 minute. Forty-four participants (4\%) did not complete all measures, and 67 participants (6\%) provided incorrect responses to one of the comprehension checks, but attrition and comprehension check accuracy did not differ by condition. Excluding these cases left us with a final sample of 937 participants (452 men; 479 women; 3 non-binary; 3 preferred not to answer; age range: 18 - 88).

\section{Materials and Procedure}

Participants were directed to an English-language online survey about reasoning about natural disasters, where they imagined themselves caught in a flash flood warning that was metaphorically framed as a vehicle or an antagonist (randomly assigned between subjects). The scenarios were the same as those presented in Study 2 with the inclusion of one sentence at the end stating either that the network's weather forecasters cannot predict the severity of the flood, forecasters expect the severity of the flood to be minor, or forecasters expect the severity of the flood to be major (severity information randomly assigned between subjects).

Participants then predicted the severity of the flood by estimating how much damage they thought would result from the flood on a 5-point scale $(1=$ no damage; $5=$ considerable 
damage). They also indicated whether they would intend to pack an evacuation bag and emergency kit if they were in this situation (no/yes).

Participants then completed comprehension check questions, where they responded to open text boxes regarding what the opening scenario was about and what was contained in a picture (of potatoes). Finally, participants completed several demographic questions and were debriefed.

\section{Results and Discussion}

\section{Did participants view the newscaster forecasts of severity as being diagnostic for estimates of} severity?

We conducted a 2 (metaphor: vehicle, antagonist) x 3 (forecaster severity: minor, ambiguous, major) between-subjects analysis of variance on estimates of flood severity ${ }^{5}$. There was an omnibus main effect of forecasted severity, $F(2,931)=200.70, p<.001, \eta_{p}^{2}=.30$. A flood forecasted as being major was estimated to be more severe $(M=4.33, S D=.74)$ than a flood that could not be forecasted $(M=4.10, S D=.80), t(931)=3.01, p=.003,95 \% \mathrm{CI}[0.07$, $0.33], r=.10$ for the planned contrast. Additionally, a flood forecasted as being minor $(M=3.06$, $S D=.95)$ was estimated to be less severe than a flood that could not be forecasted, $t(931)=$ $15.89, p<.001,95 \%$ CI $[0.92,1.18], r=.46$ for the planned contrast. Thus, the newly added line to the vignette served as a valid manipulation of diagnostic information. Minor floods seemed

\footnotetext{
${ }^{5}$ Just as in the previous studies, we checked for violations of homogeneity of variances for continuous measures, which again occurred for our severity measure $(p=.001)$. Distributions were skewed towards the upper limits of the scale for most groups. However, factorial ANOVAs provide robust results for non-normal distributions when $n>30$ per cell (Lumley et al., 2002). Given that our study had a minimum $n$ per cell of 135 and given limited nonparametric methods of testing interactions, we utilized parametric tests. However, we note that nonparametric tests of main effects (via Mann-Whitney U) yield the same conclusions.
} 
less severe than ambiguous floods, which seemed less severe than major floods. Participants clearly draw upon this information to inform their judgments of risk.

\section{Do antagonist metaphors increase perceptions of severity only when more diagnostic}

information is absent, or do they increase perceptions of severity regardless of the presence of diagnostic information?

Because antagonists are dangerous, such metaphors should increase the participants' forecasts of the flood's severity. This was indeed the case. Replicating Study 2, a flood framed as an antagonist seemed more severe $(M=3.92, S D=1.01)$ than a flood framed as a vehicle $(M=$ $3.73, S D=.98): F(1,931)=11.02, p=.001,95 \%$ CI $[.07, .29], d=.20$, for the main effect of metaphor across newscaster severity conditions. Additionally, as shown in Figure 2, the interaction between metaphor and severity was not significant, $F<1$, indicating that the effect of metaphor did not depend upon how ambiguous or unambiguous the severity of the event seemed. This combination suggests that antagonist metaphors do not merely provide risk information when more diagnostic information is absent. Rather, they function as diagnostic information for severity even when other suitable information is available. 


\section{Figure 2}

Mean $( \pm 1$ SE) forecasted flood severity by metaphoric frame and by weather forecaster severity in Study 3

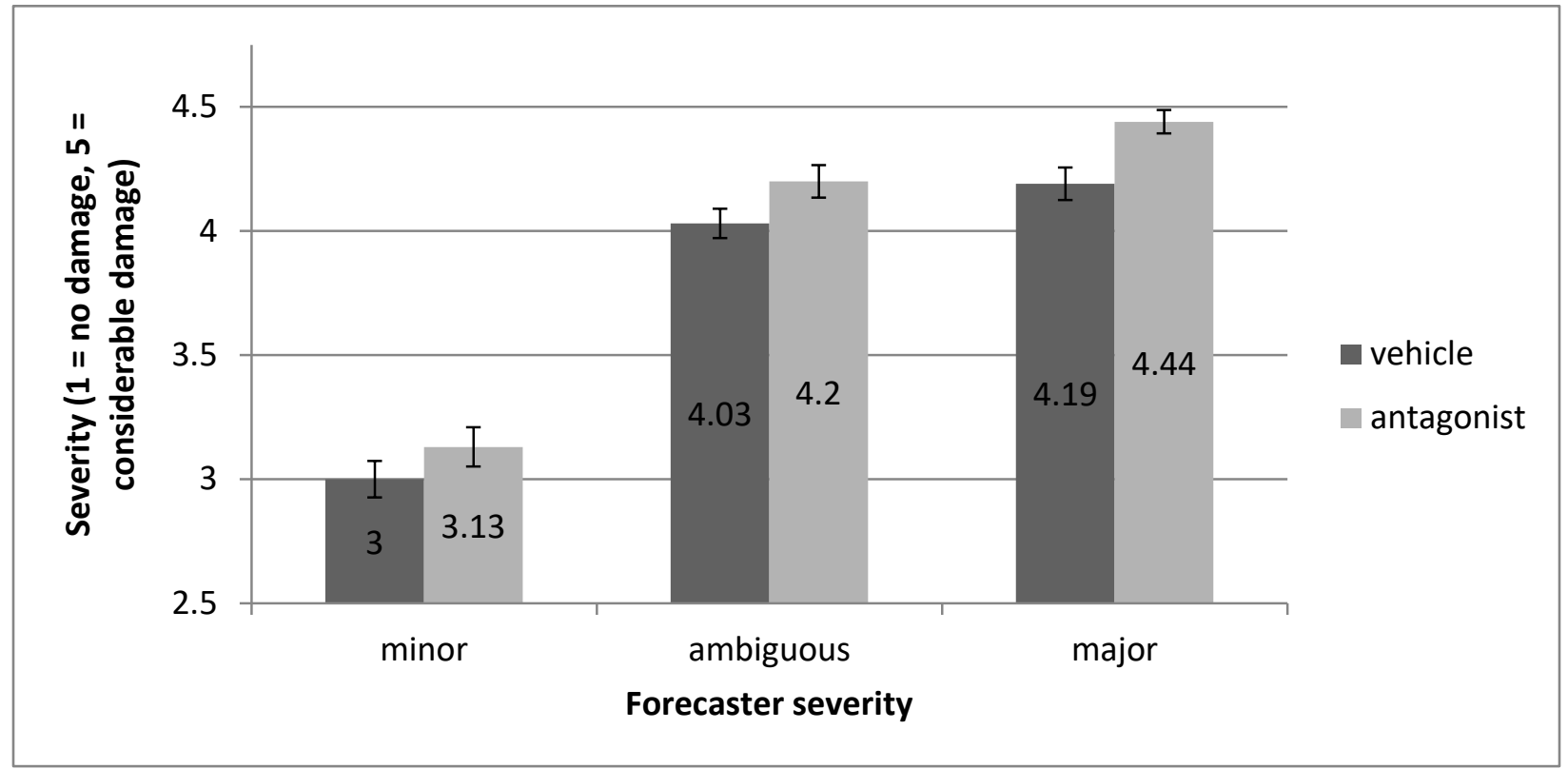

Note. Antagonist-framed floods were forecasted by participants as being more severe than vehicle framed floods, and the effect did not depend upon the severity of the flood as predicted by weather forecasters.

\section{Evacuation preparations}

Because antagonists are best avoided, such metaphors should increase the participants' intentions to make evacuation preparations. Results for this measure followed similar patterns as severity forecasts. We submitted evacuation decisions (no vs yes) to a binary logistic regression, with metaphor, severity, and their interactions entered simultaneously as mean-centered predictors. Two orthogonal contrasts for severity were included. Because the primary question was whether the effect of metaphor depended upon ambiguity, the primary contrast compared the message of ambiguous severity to the messages of minor and major severity. The secondary contrast compared the messages of minor and major severity.

As indicated by the secondary contrast, a lower proportion of participants intended to make evacuation preparations when the flood was forecasted as being minor (72\%) than when it 
was forecasted as being major $(94 \%), \beta=1.74$, Wald $=42.08, p<.001$, odds ratio $=5.72$. Thus, participants saw the severity information as being diagnostic information for evacuation decisions. However, the interaction of metaphor and the primary severity contrast was not significant, $\beta=-0.15$, Wald $=0.10, p=.751$, odds ratio $=0.86$. This again suggests that the effect of antagonist framing is not dependent upon severity information being absent. While the main effect of metaphor was not significant $[\beta=0.26$, Wald $=1.48, p=.224$, odds ratio $=1.30]$, proportions were in similar directions to those observed in prior measures and studies; a higher proportion of participants intended to make evacuation preparations for an antagonist framed flood $(87 \%)$ than a vehicle framed flood $(83 \%)$. We explore the consistency of this pattern further in the summary analysis.

\section{Summary Analyses}

We conducted a meta-analysis of the current studies to assess the strength of the evidence for the effect of antagonist metaphors on evacuation intentions. The effect of antagonist metaphoric framing vs other framing was transformed into a risk difference score in "stay" intentions (i.e., intending to not evacuate or not make evacuation preparations) for each effect. Because each study had similar designs, we used fixed effect models to estimate average risk difference score across effects using the r package metafor (Viechtbauer, 2010; Hedges \& Vevea, 1998).

As seen in the bottom row of Figure 3, the meta-analysis showed an average risk difference of $-0.05(S E=0.01, z=3.83, p<.001,95 \%$ CI $[-0.03,-0.08])$ for the effect of antagonist framing on "stay" intentions. When the natural disaster was framed as an antagonist (vs alternative framing), it reduced the percentage of participants who intended to stay by 5 percentage points on average. 


\section{Figure 3}

Forest plot of the effect of antagonist metaphoric framing (vs other framing) on percentage difference in "stay" intentions, including a fixed effects model estimate of the meta-analytic percentage difference.

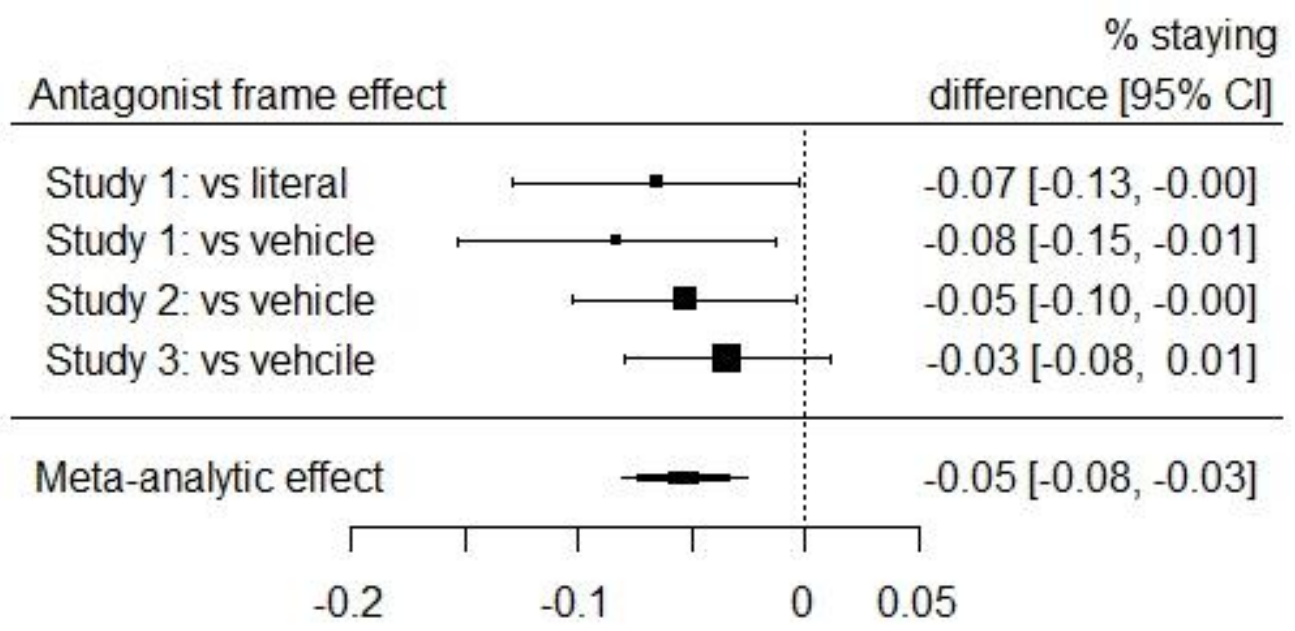

percentage point difference in intentions to stay

Note. The vertical dotted line represents no significant effect. For each row, squares represent effect sizes and bars represent $95 \%$ confidence intervals. When the natural disaster was framed as an antagonist, it significantly reduced the amount of people who intended to stay by five percentage points on average.

Meta analyses of other dependent measures were not undertaken given the lack of firm methods for meta-analyses of nonparametric effects sizes. However, Table 4 displays a summary of effect sizes for the effect of antagonist framing for the remaining dependent measures. Effect sizes appear to fall mostly within the "small" to "moderate" range. Study 1 showed larger effect sizes than Studies 2 and 3. This could be attributable to sample size; Study 1 had a smaller sample, and smaller samples tend to inflate effect size estimates (Maxwell et al., 2015). Or, this could be attributable to domain differences; Study 1 investigated metaphors for hurricanes while 
Studies 2 and 3 investigated metaphors for floods, and perhaps antagonist metaphors are less applicable to popular mental models of floods than for hurricanes (Thibodeau \& Durgin, 2011).

Table 4.

Summary of effect sizes (d) of antagonist framing vs other conditions on the dependent variables across studies

\begin{tabular}{lrr}
\cline { 2 - 3 } & $\begin{array}{r}\text { Effect size }(d) \text { of } \\
\text { antagonist (vs vehicle) }\end{array}$ & $\begin{array}{r}\text { Effect size }(d) \text { of } \\
\text { antagonist (vs literal) }\end{array}$ \\
\hline Study 1 $(N=363)$ & .27 & .39 \\
$\quad$ Homes destroyed & .52 & .47 \\
Lives lost & .39 & .26 \\
$\quad$ Days without power & .49 & .24 \\
$\quad$ Severity & & -- \\
Study 2 $(N=636)$ & .15 & - \\
$\quad$ Severity & & - \\
Study 3 $(N=937)$ & .20 & \\
$\quad$ Severity & &
\end{tabular}

\section{General Discussion}

Hurricanes and floods that "strike" an area seem more dangerous than hurricanes that "make landfall" and floods that "reach" an area. Antagonist metaphors for natural disasters increase perceptions of their severity. In natural language, concepts relating to antagonists (e.g., enemy, monster, beast) are more associated with danger (vs safety) than concepts relating to vehicles and other concepts (pilot study). When hurricanes are framed as antagonists (vs framed as vehicles or framed literally), people forecast more lives lost, more homes destroyed, more days without power, and a more severe storm. Additionally, an antagonist framed hurricane encouraged more evacuation intentions than the other frames (Study 1). Similar patterns persisted for floods framed as antagonists vs vehicles (Study 2).

Finally, people treat antagonist metaphors as diagnostic information even when other diagnostic information about severity is available. Antagonist-framed floods were perceived as 
being more severe than vehicle-framed floods even when the message contained diagnostic information about flood severity (Study 3). Thus, in natural disaster risk communication, metaphors are not merely information of a last resort, only to be drawn upon when other information is unavailable. They affect judgments even when other more diagnostic information is available. The common metaphors that pervade discourse on natural disasters have a seemingly robust effect on perceptions of their severity.

The current results suggest that the metaphorical language used to discuss natural disasters deserves consideration in the development of models of effective risk communication (Glik, 2007). Metaphors serve epistemic functions, resolving uncertainty and helping people make sense of ambiguous events (Keefer et al., 2011). Natural disasters are inherently ambiguous future events which people have strong motivations to understand and forecast, especially when they suspect that they will be impacted. Thus, it seems sensible that they seize upon the language used to discuss such events, especially when conceptual metaphors provide simple conclusions regarding severity. Because antagonist metaphors for natural disasters are commonplace (Matlock et al., 2017), they serve as common mental models that people use to reason about such events (Johnson-Laird, 1983; Morgan et al., 2002). Thus, it is important to know that such metaphors are not merely linguistic flourishes that can be added or removed from messages without impacting perceptions. Message recipients draw upon them to ascertain severity and plan behaviour, so such language needs attention and further investigation.

While antagonist agent metaphors increase the perceived severity of natural disasters, it is important to note that further research is necessary in order to shed light on the full spectrum of inferences such metaphors promote. We hypothesized they would impact severity estimates because of common associations of antagonists with danger. However, antagonists may have 
entailments for other attributes of natural disasters. For instance, antagonists tend to have agency and intentionality, and such framing tends to promote inferences that concepts will continue along current trajectories (Morris et al., 2007). Applied to natural disasters, such metaphors may affect inferences of where the event will strike, increasing the perceived danger for those within a projected path but decreasing it for those outside a projected path. Additionally, our studies examined lay audiences, but narrative information such as metaphors may carry less weight for experts (Dieckmann et al., 2009). Nuances such as these may prove fruitful for future research to explore.

While our studies measured evacuation intentions as an outcome of interest, we note that our measure is not parallel across studies. Study 1 asked participants whether they would evacuate while Study 2 and Study 3 asked participants if they would make evacuation preparations (i.e., pack an evacuation bag and emergency kit). Many factors aside from perceived severity of the weather event motivate evacuation behaviour, including education, income, and personal risk (Whitehead et al., 2000). Antagonist metaphors are just one of many factors.

Finally, while we designed the stimuli to vary between antagonist metaphors, vehicle metaphors, and literal frames, there may have been additional metaphorical differences between conditions and studies that are difficult to control. For instance, the literal condition in Study 1 may have contained "journey" metaphors (e.g., the "arrival" of the hurricane) and personification metaphors (e.g., the hurricane "swept through"). Additionally, the vehicle condition in Studies 2 and 3 may not have evoked a vehicle schema to the same degree as the vehicle condition in Study 1 . These are frequent consequences of attempting to apply metaphors to different domains while also attempting to craft fluent messages that participants comprehend. While the effect of 
antagonist frames (vs other frames) appears reliable across studies, the current research may be limited in its ability to forecast the unique effects of vehicle or literal frames.

The current results carry implications for how media discuss natural disasters. Television meteorologists on local news programs are trusted sources of climate information for many (Maibach et al., 2016). If a severe weather event is imminent, ought meteorologists leverage antagonist frames to encourage evacuation preparations? If a weather event is forecasted to be severe and evacuation is strongly suggested by authorities, we think yes. Study 3 found that even when a local meteorologist unambiguously forecasted a flood as being severe, describing the flood with antagonist metaphors further increased its perceived danger. Antagonist metaphors may be useful for establishing injunctive norms (i.e., norms for what people ought to do) that benefit public health in these circumstances. However, descriptive norms (i.e., norms for what people actually tend to do) are far more powerful at guiding behaviour (Cialdini et al., 1991). So, if evacuation is necessary, mandatory evacuation orders will be far more effective than antagonist metaphors.

Additionally, like all persuasive tactics, antagonist metaphors in newscasts may be subject to source credibility effects (for a review, see Kelman \& Hovland, 1953). People living in disaster-prone areas are often able to recall past forecasts of "dangerous weather events" that were overblown (Eisenman et al., 2007), causing them to doubt the credibility of all severe weather warnings. Antagonist metaphors may not have any impact if they come from sources that lack credibility. Future research could manipulate the credibility of a new source, crossed with metaphoric frame (antagonist vs control), to see if "monster" storms on less credible news sources still garner the same increases in risk perception that they do in our studies. 
Overall, antagonist metaphors for natural disasters increase perceptions of their severity. Mere mention of a hurricane "striking" a region (as opposed to "making landfall at" a region) increased estimates of how much damage would ensue as well as increased the proportion of people who intended to evacuate. These patterns persisted even when more diagnostic information was available. Because antagonist metaphors commonly frame natural disasters in popular media and news broadcasts, designers of risk communications should be aware that such metaphors are not mere linguistic flourishes. Rather, they convey meaningful information that people draw upon to infer risk and plan behaviour. 


\section{References}

Anderson, N. H. (1971). Integration theory and attitude change. Psychological Review, 78, 171206.

Asch, S. E. (1946). Forming impressions of personality. The Journal of Abnormal and Social Psychology, 41(3), 258.

Bhatia, S. (2017). Associative judgment and vector space semantics. Psychological Review, 124(1), 1-20.

Caliskan, A., Bryson, J. J., \& Narayanan, A. (2017). Semantics derived automatically from language corpora contain human-like biases. Science, 356(6334), 183-186.

Cialdini, R. B., Kallgren, C. A., \& Reno, R. R. (1991). A focus theory of normative conduct: A theoretical refinement and reevaluation of the role of norms in human behavior. In Advances in experimental social psychology (Vol. 24, pp. 201-234). Academic Press.

CNN. (2019, October 30). Hurricane Katrina statistics fast facts. Retrieved from https://www.cnn.com/2013/08/23/us/hurricane-katrina-statistics-fast-facts/index.html.

Cuddy, A. J., Fiske, S. T., \& Glick, P. (2008). Warmth and competence as universal dimensions of social perception: The stereotype content model and the BIAS map. Advances in Experimental Social Psychology, 40, 61-149.

Davies, M. (2016) Corpus of News on the Web (NOW): 10 billion words from 20 countries, updated every day. Available online at https://www.english-corpora.org/now/.

Dieckmann, N. F., Slovic, P., \& Peters, E. M. (2009). The use of narrative evidence and explicit likelihood by decisionmakers varying in numeracy. Risk Analysis: An International Journal, 29(10), 1473-1488. 
Eisenman, D. P., Cordasco, K. M., Asch, S., Golden, J. F., \& Glik, D. (2007). Disaster planning and risk communication with vulnerable communities: Lessons from Hurricane Katrina. American Journal of Public Health, 97(Supplement_1), S109-S115.

Faul, F., Erdfelder, E., Buchner, A., \& Lang, A. G. (2009). Statistical power analyses using G* Power 3.1: Tests for correlation and regression analyses. Behavior Research Methods, 41(4), 1149-1160.

Flusberg, S. J., Matlock, T., \& Thibodeau, P. H. (2017). Metaphors for the war (or race) against climate change. Environmental Communication, 11(6), 769-783.

Flusberg, S. J., Matlock, T., \& Thibodeau, P. H. (2018). War metaphors in public discourse. Metaphor and Symbol, 33(1), 1-18.

Gentner, D. (1983). Structure-mapping: A theoretical framework for analogy. Cognitive Science, $7(2), 155-170$.

Gibbs, R. W. (1994). The poetics of mind: Figurative thought, language, and understanding. Cambridge, England: Cambridge University Press.

Glik, D. C. (2007). Risk communication for public health emergencies. Annual Review of Public Health, 28, 33-54.

Hauser, D. J. \& Schwarz, N. (2015). The war on prevention: Bellicose cancer metaphors hurt (some) prevention intentions. Personality and Social Psychology Bulletin, 41, 66-77.

Hauser, D. J. \& Schwarz, N. (2016). Attentive Turkers: MTurk participants perform better on online attention checks than subject pool participants. Behavior Research Methods, 48, 400-407.

Hauser, D. J. \& Schwarz, N. (2016). Medical metaphors matter: Experiments can determine the impact of metaphors on bioethical issues. American Journal of Bioethics, 16, 18-19. 
Hauser, D. J., Nesse, R. M., \& Schwarz, N. (2017). Lay theories and metaphors of health and illness. In Zedelius C., Muller, B., \& Schooler J. W. (Eds.) The science of lay theories: How beliefs shape our culture, cognition, and health. (pp. 341-354). Springer.

Hauser, D. J., Paolacci, G., \& Chandler, J. (2019). Common concerns with MTurk as a participant pool: Evidence and solutions. In F. R. Kardes, P. M. Herr, \& N. Schwarz (Eds.), Handbook of Research Methods in Consumer Psychology. (pp. 319-337). Routledge.

Hauser, D. J. \& Schwarz, N. (2020). The war on prevention II: Battle metaphors undermine cancer treatment and prevention and do not increase vigilance, Health Communication, 17.

Hedges, L. V., \& Vevea, J. L. (1998). Fixed-and random-effects models in meta-analysis. Psychological Methods, 3(4), 486.

Higgins, E. T. (1996). Knowledge activation: Accessibility, applicability, and salience. In E. T. Higgins \& A. W. Kruglanski (Eds.), Social psychology: Handbook of basic principles (pp. 133-168). New York: Guilford Press.

Holyoak, K. J., \& Stamenković, D. (2018). Metaphor comprehension: A critical review of theories and evidence. Psychological Bulletin, 144(6), 641-671.

Johnson-Laird, P. N. (1983). Mental models: Towards a cognitive science of language, inference, and consciousness (No. 6). Harvard University Press.

Kahneman, D., \& Tversky, A. (1973). On the psychology of prediction. Psychological Review, 80(4), 237.

Keefer, L. A., Landau, M. J., Sullivan, D., \& Rothschild, Z. K. (2011). Exploring metaphor's epistemic function: Uncertainty moderates metaphor-consistent priming effects on social perceptions. Journal of Experimental Social Psychology, 47(3), 657-660. 
Kelman, H., \& Hovland, C. (1953). "Reinstatement" of the communicator in delayed measurement of opinion change. The Journal of Abnormal and Social Psychology, 48(3), $327-335$.

Keysar, B., \& Bly, B. (1995). Intuitions of the transparency of idioms: Can one keep a secret by spilling the beans? Journal of Memory and Language, 34, 89-89.

Kilpijärvi, H. (2014). "She is eyeing the Outer Banks": Referring expressions and conceptual metaphors used in hurricane-related news. (Unpublished Post-Doctoral Thesis). University of Tampere, Finland. https://pdfs.semanticscholar.org/30bc/81cd3461479ca1c2aebf790a1f408281d920.pdf Kujawa, A., Hajcak, G., Danzig, A. P., Black, S. R., Bromet, E. J., Carlson, G. A., ... \& Klein, D. N. (2016). Neural reactivity to emotional stimuli prospectively predicts the impact of a natural disaster on psychiatric symptoms in children. Biological psychiatry, 80(5), 381389.

Lakoff, G., \& Johnson, M. (1980). Metaphors We Live By. Chicago: University of Chicago Press.

Landau, M. J., Arndt, J., \& Cameron, L. D. (2018). Do metaphors in health messages work? Exploring emotional and cognitive factors. Journal of Experimental Social Psychology, 74, 135-149.

Landau, M. J., Keefer, L. A., \& Rothschild, Z. K. (2014). Epistemic motives moderate the effect of metaphoric framing on attitudes. Journal of Experimental Social Psychology, 53, 125138.

Landau, M. J., Meier, B. P., \& Keefer, L. A. (2010). A metaphor-enriched social cognition. Psychological Bulletin, 136(6), 1045. 
Lee, S. W. S., Schwarz, N. (2014). Metaphors in judgment and decision making. In M. J. Landau, M. D. Robinson, \& B. P. Meier (Eds.), The power of metaphor: Examining its influence on social life (pp. 85-108). Washington, DC: APA.

Lee, S. W., \& Schwarz, N. (2011). Wiping the slate clean: Psychological consequences of physical cleansing. Current Directions in Psychological Science, 20(5), 307-311.

Lee, S. W., \& Schwarz, N. (2014). Framing love: When it hurts to think we were made for each other. Journal of Experimental Social Psychology, 54, 61-67.

Litman, L., \& Robinson, J. (2020). Conducting online research on Amazon Mechanical Turk and beyond. Sage Publications.

Lumley, T., Diehr, P., Emerson, S., \& Chen, L. (2002). The importance of the normality assumption in large public health data sets. Annual Review of Public Health, 23,151-169.

Maibach, E., Placky, B. W., Witte, J., Seitter, K., Gardiner, N., Myers, T., ... \& Cullen, H. (2016). TV meteorologists as local climate change educators. In Oxford research encyclopedia of climate science.

Matlock, T., Coe, C., \& Westerling, A. L. (2017). Monster wildfires and metaphor in risk communication. Metaphor and Symbol, 32(4), 250-261.

Maxwell, S. E., Lau, M. Y., \& Howard, G. S. (2015). Is psychology suffering from a replication crisis? What does "failure to replicate" really mean? American Psychologist, 70(6), 487.

Mikolov, T., Chen, K., Corrado, G., \& Dean, J. (2013). Efficient estimation of word representations in vector space. arXiv preprint arXiv:1301.3781.

Morgan, M. G., Fischhoff, B., Bostrom, A., \& Atman, C. J. (2002). Risk communication: A mental models approach. Cambridge University Press. 
Morris, M. W., Sheldon, O. J., Ames, D. R., \& Young, M. J. (2007). Metaphors and the market: Consequences and preconditions of agent and object metaphors in stock market commentary. Organizational Behavior and Human Decision Processes, 102(2), 174-192.

Owens, S. (2000). 'Engaging the public': Information and deliberation in environmental policy. Environment and Planning A, 32(7), 1141-1148.

Public Safety Canada. (2018). The Canadian disaster database. Retrieved from https://www.publicsafety.gc.ca/cnt/rsrcs/cndn-dsstr-dtbs/index-en.aspx.

Robins, S., \& Mayer, R. E. (2000). The metaphor framing effect: Metaphorical reasoning about text-based dilemmas. Discourse Processes, 30(1), 57-86.

Scherer, A. M., Scherer, L. D., \& Fagerlin, A. (2015). Getting ahead of illness: Using metaphors to influence medical decision making. Medical Decision Making, 35(1), 37-45.

Slepian, M. L., \& Ambady, N. (2014). Simulating sensorimotor metaphors: Novel metaphors influence sensory judgments. Cognition, 130(3), 309-314.

Thibodeau P. H., \& Boroditsky, L. (2015). Measuring effects of metaphor in a dynamic opinion landscape. PLoS One, 10(7): e0133939.

Thibodeau, P. H., \& Boroditsky, L. (2011). Metaphors we think with: The role of metaphor in reasoning. PloS One, 6(2).

Thibodeau, P. H., \& Durgin, F. H. (2011). Metaphor aptness and conventionality: A processing fluency account. Metaphor and Symbol, 26(3), 206-226.

Thibodeau, P. H., Hendricks, R. K., \& Boroditsky, L. (2017). How linguistic metaphor scaffolds reasoning. Trends in cognitive sciences, 21(11), 852-863.

Thibodeau, P. H., Matlock, T., \& Flusberg, S. J. (2019). The role of metaphor in communication and thought. Language and Linguistics Compass, 13(5), e12327. 
Viechtbauer, W. (2010). Conducting meta-analyses in R with the metafor package. Journal of Statistical Software, 36(3), 1-48.

Whitehead, J. C., Edwards, B., Van Willigen, M., Maiolo, J. R., Wilson, K., \& Smith, K. T. (2000). Heading for higher ground: Factors affecting real and hypothetical hurricane evacuation behavior. Global Environmental Change Part B: Environmental Hazards, 2(4), 133-142.

Williams, L. E., Huang, J. Y., \& Bargh, J. A. (2009). The scaffolded mind: Higher mental processes are grounded in early experience of the physical world. European Journal of Social Psychology, 39(7), 1257-1267. 